\title{
To Do or Not to Do? -A Review of Cancer Surgery Triage Guidelines in COVID-19 Pandemic
}

\author{
Rajesh S. Shinde ${ }^{1,2}$ (D) Mekhala D. Naik ${ }^{3}$ - Shital R. Shinde ${ }^{4}$ Manish S. Bhandare ${ }^{5}$. Vikram A. Chaudhari ${ }^{5}$. \\ Shailesh V. Shrikhande ${ }^{5}$. Anil K. Dcruz ${ }^{1,2}$
}

Received: 20 April 2020 / Accepted: 28 April 2020 / Published online: 11 May 2020

(C) Indian Association of Surgical Oncology 2020

\begin{abstract}
COVID-19 pandemic has emerged as a global health emergency involving more than 200 countries so far. The number of affected population is on rising, so is the mortality. This crisis has overwhelmed the healthcare infrastructures in many affected countries. Due to overall rising cancer incidence and specific concerns, a cohort of cancer patients forms a distinct subset of the population in whom a correct and timely treatment has a huge impact on the outcome. During this period, oncology care is definitely affected owing to many factors like lockdowns, reduced beds and deferral of elective cases to halt the spread of the pandemic. Surgery remains the best line of defence in many solid organ tumours especially in early stage and is potentially curative. China, the source of this pandemic, has taken more than 3 months to enter the post transitional phase of this pandemic. Deferring cancer surgeries for this long period may have a direct impact on the long-term outcomes of cancer patients. Many surgical oncology associations across the globe have come up with triage guidelines for surgical care of cancer patients; however, these are based on expert opinion rather than actual data. Herein, we intend to review these guidelines with respect to the risk of disease progression in cancer patients. In the absence of actual data on cancer surgery care during this pandemic, clinical decisions should be based on careful consideration of disease-related and patient-related factors. While some of the cancer surgeries can be safely delayed for some time, how long we can delay surgeries safely cannot be answered/ explained by any means. Thorough evaluation and discussion by an expert and experienced multidisciplinary team appears to be the most effective way forward.
\end{abstract}

Keywords Cancer $\cdot$ Surgery $\cdot$ Triage $\cdot$ Guidelines

\section{Introduction}

In the new decade, our world woke up to a new medical challenge: the SARS COVID-19 pandemic. As of March 31,

Rajesh S. Shinde

dr.rajeshinde@gmail.com; dr.rajeshinde@icloud.com

1 Department of Surgical Oncology, Gastrointestinal Cancer Surgery, Apollo Hospitals, Navi Mumbai, India

2 Department of Surgical Oncology, Gastrointestinal Cancer Surgery, Bombay Hospital Institute of Medical Sciences, Mumbai, India

3 Department of Urology, Bombay Hospital Institute of Medical Sciences, Mumbai, India

4 Department of Anaesthesia, LTMMGH, Sion, Mumbai, India

5 Department of Surgical Oncology, Tata Memorial Hospital, Homi Bhabha National Institute, Mumbai, India
2020 , this pandemic has affected 801,400 people and killed 38,743 people across the globe. The experience from China, the source of the outbreak, and other countries affected by the pandemic has shown the magnitude by which healthcare facilities can be overwhelmed during this crisis. Worldwide measures to 'flatten the curve' of this medical emergency have been implemented, so as to buy time for the national healthcare infrastructure and resources to gear up to deal with this catastrophic illness. Hospitals also face a challenge to cater the needs of their existing sick patients, particularly those with malignancies. With this pressure on healthcare facilities combined with other realities of increasing cancer incidence, the need for special resources in oncology care, guarded prognosis in many malignancies and semi-emergent nature and need of cancer treatment, it is extremely difficult for an oncology healthcare personnel to decide who gets treatment for cancer and who has to wait. While the oncologist makes this judgement, they welter between maintaining a balance 
between logical and philosophical decision making during this crisis. As cancer surgeries involve significant healthcare resources in terms of infrastructure, intensive care unit beds, blood products and manpower, surgical oncologists face a dilemma regarding the triage of surgical patients during this period of uncertainty. Guidelines, laid by professional organisations like the Society of Surgical Oncology (SSO), American Cancer Society (ACS), European Association of Urology (EAU), Indian Association of Surgical Oncology (IASO) and Federation of Head Neck Oncology (FHNO) are predominantly based on expert opinions and are vague at places. Herein, we intend to review triage guidelines for cancer surgery, laid down by these associations around the globe.

\section{Lessons from the Past}

COVID-19 is the sixth global public health emergency in the history as declared by WHO. The two epidemics in recent past, SARS-CoV (2002-2003) and the MERS-CoV (20122015), have given us insight into how closely these three manifest, albeit SARS COVID-19 has emerged to be more lethal than the other two [1]. These epidemics have taught us to initiate response interventions in the form of early detection, containment, control and mitigation [2]. Sadly, there is a dearth of literature from SARS and MERS epidemics on experience and implications in the field of cancer surgery.

\section{The 'Novel' Virus}

The novel coronavirus (SARS-CoV-2) has been documented to have an efficient human to human transmission process via airborne, droplet and contact routes. Unlike the SARS-CoV, patients of SARS-CoV-2 can transmit the infection during the incubation period as well [3]. The age group with the highest risk for acquiring primary and secondary cases of infection is 50-65 years (most cancers are found in the same age group). About $50 \%$ of patients have a subclinical infection, $30 \%$ have mild to moderate symptoms and $20 \%$ can develop severe symptoms with $5-10 \%$ requiring ICU care and ventilatory requirement. Symptoms common to most coronavirus infections are fever, chills, generalized myalgia, drowsiness, cough, shortness of breath, abdominal pain, nausea, vomiting and diarrhoea. The median duration of viral shedding is about 20 days and longest known to be 37 days, with continue shedding until death, unaltered by the administration of antiviral drugs such as Ritonavir and Lopinavir [4]. The median time of requirement of invasive mechanical ventilation reported is 14.5 days, and the median time to death being 18.5 days [4]. Sepsis, followed by respiratory failure, adult respiratory distress syndrome (ARDS), heart failure, acute kidney injury, shock and secondary infections (including ventilator- associated pneumonia) are the common complications with severe infections [4]. The virus can be isolated from oropharyngeal and respiratory secretions and also in stool samples of affected individuals. However, the virus has not been isolated in the blood or urine [5]. The World Health Organization (WHO) and Centre for Disease Control and Prevention (CDC) recommend RT-PCR for laboratory diagnosis of SAR-CoV-2 [6]. China, where the pandemic started, has now entered the post pandemic or the transitional phase, and clinical epidemiological data from China can prove to be a guiding light for the management of cases. So far social distancing, a modern form of quarantine, has proven to be the most effective preventive strategy for containment of this pandemic. Two drugs, remdesivir and hydroxychloroquine, have shown in vitro efficacy against SARS-CoV-2 [7, 8]. Further population studies with these drugs are awaited, and it will take another few months till we have a vaccine for SARSCoV-2.

\section{Oncology Patient Cohort-A Special Set of Population}

According to the GLOBOCAN 2018, globally, there were 18.1 million new cancer cases and 9.6 million cancer deaths in 2018 with a speculated increasing trend in overall incidence [9]. Cancer patients are at heightened risk for infection owing to suppressed immunity due to the malignancy per se and secondary to the effect of chemotherapy, radiotherapy and surgery. Also, reports have shown an increased rate of complications, need for ventilatory support, admission to intensive care units, overall poor prognosis and death in cancer patients with COVID-19 infection. A particular concern for a cancer surgeon is to weigh the risk of deferring cancer surgery versus the risk of COVID-19 exposure and infection to patients as well as health care providers. Disruptions in outbreak mitigation strategies like social distancing and prudent utilization of limited health resources also need consideration in this regard $[10,11]$.

\section{Cancer Surgery in COVID-19 Outbreak}

Cancer surgeries utilise substantial resources in a hospital including diagnostic modalities, blood products, ICU beds and even ventilators. Hence, it is imperative to carefully decide the treatment plan for every patient by involving the multidisciplinary team, deciding which ones can safely be kept on the waiting list or started any bridging therapy until surgery. Existing COVID-19 cases, less volunteers for blood donation due to lockdown and rejection of donors due to history of exposure, symptoms and SARS-CoV-2 positivity can further dwindle the availability of the blood and blood products. 
Although there exists a theoretical risk of transmission of the virus in blood products, currently there is no data suggesting transmission of SARS CoV-2 by transfusion. However, the American Association of Blood Banks and European Center for Disease prevention and Control (ECDC) have suggested deferral of blood donation by patients with a history of probable exposure and travel (by 3 weeks) and COVID positive cases (by 4 weeks). However, routine screening of donors is not yet recommended $[12,13]$. Published Chinese reports on the outcomes of cancer patients infected with COVID-19 indicated a 3.5 times higher risk of needing mechanical ventilation or ICU admission or dying compared with patients without cancer [10]. Thus altogether, subjecting a cancer patient to surgery has its own risks to the patient and burdening the hospital resources. However, delaying the cancer surgeries have other implications like an increased extent of surgery in the event of cancer progression, increased perioperative morbidity/mortality and also missing a chance of offering cure due to disease spread caused by waiting. These facts cannot be overseen, also, cancer is a bigger problem than COVID-19 from patient's perspective. Table 1 summarises various studies addressing the impact of time to treatment initiation or delaying surgeries on cancer survival [14-27]. Keeping these concerns in mind, some guidelines have recommended a possible triage (Table 2) to offer surgeries, even during the course of an active pandemic, for certain precarious malignancies who are known to have rapid progression.

\section{Anaesthesia-Related Concerns}

Surgical intervention on asymptomatic infected patients in standard operating theatres without negative pressure capability can have devastating consequences exposing operating room personnel including surgeons, anaesthetists and nursing staff to a significant risk and due precautionary measures are needed. The American Association of Anaesthetists has provided excellent guidelines to follow during this pandemic. Some of the important measures are attention to surface and equipment cleaning during and between cases, regular glove changing, regular handwashing, avoiding high flow devices especially if not using personal protective equipment (PPE), video laryngoscopy assisted intubation where possible and ensuring appropriate disinfection procedures. Airway manipulation puts the anaesthetist and all healthcare workers at exposure to aerosols from the patient. Aerosol generating procedures during administration of general anaesthesia include bag and mask ventilation, endotracheal intubation and open airway suctioning. It is preferable to use regional anaesthesia wherever feasible, with added advantage of less effect on pulmonary function as compared to general anaesthesia [31-36]. Considering the significant risk of COVID transmission related to anaesthesia, it is prudent to defer the non-emergent surgical interventions. However, cancer surgeries cannot truly be considered as non-emergent interventions as there is a real risk of disease progression during the waiting period.

\section{Individual Organ System Considerations}

\section{Gastrointestinal and Hepatobiliary Cancers}

The SARS-CoV-2 is shed in intestinal cells. Also, the human colorectal adenocarcinoma-derived LoVo cell line has been shown to be susceptible to SAR-CoV producing a sustainable infection which persists after multiple passages. Intestinal biopsies from infected patients have demonstrated viral particles on electron microscopy without any lytic effects or inclusion bodies on light microscopy [37]. The SARS-CoV and SARSCoV-2 are closely related and possible feco-oral transmission of the virus has also been suggested. Hence, any elective gastrointestinal surgery/endoscopic procedures can pose a threat of transmission to surgeons and health care workers. Cases that clearly require emergency intervention like obstruction, perforation and massive bleeding obviously cannot be deferred. $\mathrm{Hu}$ et al. [38], Yu $\mathrm{G}$ et al. [39], Luo et al. [40] and Chen et al. [41] have reported their experience in managing colorectal and gastrointestinal malignancies during this pandemic and recommended stage-based treatment strategies. The American College of Surgeons [28] and Society of Surgical Oncology [29] have also suggested their take on the same issue; however, these are based on expert opinion rather than any strong evidence.

As cancer surgeons, one has to be aware about the prevention strategies for SARS-CoV-2 and implement this information into clinical practice to halt the spread of this pandemic. Neoadjuvant therapy should be offered wherever possible in advanced gastrointestinal cancers. Obstructing growths of gastroesophageal junction or colon without signs of peritonitis should be offered endoscopic stents wherever feasible. For bleeding tumours, Transcatheter arterial embolization is an option if facilities are available. Liver malignancies amenable to ablation, transarterial embolization and stereotactic surgery should be tackled accordingly [29]. Pre-admission screening of every patient to rule out asymptomatic infection and RTPCR panel with chest CT scan for patients with fever (> $37.3^{\circ} \mathrm{C}$ ), travel history and positive contact history is recommended for gastrointestinal cancer patients due for surgery. Extra precautionary measures should be taken for medical staff involved in the surgical procedures. Local governing authorities should be informed if one has to perform any emergency surgery on SARS-CoV-2-infected patient. Cytoreductive surgeries with or without HIPEC for peritoneal surface malignancies of low-grade malignancies can be deferred. Post neoadjuvant therapy cases can continue with therapy [29]. Chinese studies have recommended a laparoscopic 
Table 1 Various studies addressing the impact of waiting time/TTI on cancer survival/prognosis

\begin{tabular}{|c|c|c|c|c|}
\hline Author, year [Ref] & No of patients & Malignancy & Time to surgery & Salient features \\
\hline Kristian et al. 2020 [14] & - & Urinary bladder & - & $\begin{array}{l}\text { Delay in cystectomy by }>90 \text { days for MIBC increases } \\
\text { pN+ rate, decreases OS, DFS and higher pathologic } \\
\text { stage }\end{array}$ \\
\hline Furukawa et al. 2019 [15] & 696 & Stomach & Up to 90 days & $\begin{array}{l}\text { Preoperative wait time up to } 90 \text { days does not affect } \\
\text { survival in patients with stage II/III gastric cancer. }\end{array}$ \\
\hline Visser et al. 2016 [16] & 351 & Oesophagus & $\begin{array}{l}8 \text { weeks versus } \\
>8 \text { weeks }\end{array}$ & $\begin{array}{l}\text { Post NACT-Surgery within } 8 \text { weeks or beyond } 8 \text { weeks } \\
\text { has no impact on DFS or OS. }\end{array}$ \\
\hline Bleicher et al. 2015 [17] & 94,544 & Breast & $<30$ versus $>30$ days & $\begin{array}{l}\text { Significant difference in DFS and OS in early breast } \\
\text { cancer. }\end{array}$ \\
\hline Shin et al. 2013 [18] & 7529 & $\begin{array}{l}\text { Colorectal, breast, } \\
\text { thyroid, lung }\end{array}$ & 12 weeks & $\begin{array}{l}\text { More than } 12 \text { weeks' delay is associated with increased } \\
\text { mortality in colorectal, breast but not thyroid/lung } \\
\text { cancers. }\end{array}$ \\
\hline Fossati et al. 2017 [19] & 2653 & Prostate & 12 months & Surgical treatment can be postponed up to 12 months. \\
\hline Khorana et al. 2019 [20] & $3,672,561$ & $\begin{array}{l}\text { Pancreas, lung, } \\
\text { breast, kidney, } \\
\text { colorectal }\end{array}$ & Median TTI-27 days & $\begin{array}{l}\text { Increased TTI is associated with absolute increased risk } \\
\text { of mortality in early-stage breast, lung, renal and } \\
\text { pancreas cancers. }\end{array}$ \\
\hline Murphy et al. 2016 [21] & 51,655 & Head neck & $\begin{array}{l}<30 \text { days versus } \\
\quad 60-90 \text { days }\end{array}$ & $\begin{array}{l}\text { Increased mortality beyond } 46-52 \text { days, detrimental } \\
\text { beyond } 60 \text { days. }\end{array}$ \\
\hline Dolly et al. 2016 [22] & 889 & Endometrium & Mean 48 days & Decreased survival with increased delay \\
\hline Jeon et al. 2017 [23] & 2863 & PTC & $<12$ versus $>12$ months & No difference in recurrence/disease free survival \\
\hline Froehner et al. 2016 [24] & 1 & Kidney & 30 days & $\begin{array}{l}\text { Rapid increase in the level of tumour thrombus } \\
\text { with delay }\end{array}$ \\
\hline Waldert et al. 2009 [25] & 187 & UTUC & $<3$ versus $>3$ months & $\begin{array}{l}\text { Delay to surgery is associated with disease } \\
\text { progression but not with mortality or recurrence. }\end{array}$ \\
\hline Baudin et al. 2015 [26] & - & Adrenal & - & $\begin{array}{l}\text { ACC progresses rapidly and delay may decrease } \\
\text { resectability and affect survival. }\end{array}$ \\
\hline Kabir et al. 2020 [27] & 863 & $\mathrm{HCC}$ & $<30$ versus $>30$ days & Time to surgery does not affect OS. \\
\hline
\end{tabular}

$T T I$ time to treatment initiation, NACT neoadjuvant chemotherapy, DFS disease-free survival, $O S$ overall survival, $P T C$ papillary thyroid cancer, $U T U C$ upper urothelial tract urothelial carcinoma, $M I B C$ muscle invasive bladder cancer, $H C C$ hepatocellular carcinoma, $A C C$ adrenocortical carcinoma

approach over open for colorectal surgeries; however, the measure to contain the aerosol dissemination during pneumoperitoneum has to be dealt with care [40, 41].

\section{Thoracic Cancers}

This cohort represents patients with a higher risk for deterioration of pulmonary function secondary to existing lung diseases, pneumonitis due to other infections, radiation pneumonitis, immune checkpoint inhibitor-associated pneumonia and tumour progression all which can mask an underlying SARSCoV-2 infection. CT imaging is essential for the diagnosis of SARS-CoV-2 infection in the absence of microbiological tests and the CT picture might be confusing in these patients. Hence, a careful history of exposure, along with strong index suspicion, is required to rule out COVID-19. Smoking, one of the commonest risk factors in lung cancer, has not been independently shown to affect the mortality in SARS-CoV-2 patient; however, pre-existing chronic obstructive lung disease is associated with increased mortality [4]. Perforated oesophageal malignancies, threatened airways, anastomotic leaks, bleeding, post-operative complications like hemothorax, and empyema need immediate intervention and need to be taken to theatre on priority basis [28]. Tian et al. [42] reported postoperative mortality in one out of two patients with lung cancer, who were detected SARS-CoV-2-positive after surgery. Xin et al. [43], Yan et al. [44] have reported specific recommendations for the management of lung cancer in the COVID-19 epidemic, but these articles are published only in the Chinese language and hence difficult to interpret for others.

\section{Head Neck Cancers}

Oropharyngeal malignancies pose a clear threat of aerosol exposure even with simple clinical examination. Elective surgery of the upper airways requiring mandatory post-operative assisted mechanical ventilation, elective tracheostomies and extensive reconstructions should be preferably be deferred on case-to-case basis. Direct and fibre optic laryngoscopy should be deferred. If it has to be done, then use adequate anaesthesia, avoid looking directly through the lens and attach a monitor. Neck node FNAC can be opted over endoscopic 
additional 2-3 weeks on case-to-case basis. Those with progressive disease on systemic therapy, angiosarcoma and malignant phyllode tumours should be offered surgery on a priority basis. Most surgeries for endocrine tumours can be postponed, unless those with impending airway threat, pheochromocytoma and functional neuroendocrine tumours refractory to medical management. Gynaecological malignancies can be aggressive if delayed, hence most guidelines recommended to go ahead with surgery wherever feasible. Infections including joints and impending pathological fractures including periprosthetic fractures, soft tissue extremity sarcomas in the radiation or chemotherapy window and aggressive benign tumours like giant cell tumours should be offered surgical interventions as and when required [28-30,45].

To summarise, in the absence of actual data on cancer surgery care during this pandemic, clinical decisions should be based on careful consideration of disease-related and patientrelated factors. While some of the cancer surgeries can be safely delayed for some time, how long we can delay surgeries safely cannot be answered/explained by any means. Thorough evaluation and discussion by an expert and experienced multidisciplinary team appears to be the most effective way forward; however, the pandemic is likely to have an adverse impact on a number of cancer patients due to the inevitable delay caused in their treatment. In the future, while such pandemics may still crop up and cannot be prevented, the health care system and infrastructure should be boosted in anticipation, to combat illnesses such as cancer during these natural calamities.

\section{Compliance with Ethical Standards}

\section{Conflict of Interest None}

\section{References}

1. Meo SA, Alhowikan AM, Al-Khlaiwi T et al (2020) Novel coronavirus 2019-nCoV: prevalence, biological and clinical characteristics comparison with SARS-CoV and MERS-CoV. Eur Rev Med Pharmacol Sci 24(4):2012-2019

2. World Health Organisation (2019) Managing epidemics: key facts about major deadly diseases. https://www.who.int/emergencies/ diseases/managing-epidemics/en/

3. Zou L, Ruan F, Huang M, Liang L, Huang H, Hong Z, Yu J, Kang M, Song Y, Xia J, Guo Q, Song T, He J, Yen HL, Peiris M, Wu J (2020) SARS-CoV-2 viral load in upper respiratory specimens of infected patients. N Engl J Med 382(12):1177-1179

4. Zhou F, Yu T, Du R et al (2020) Clinical course and risk factors for mortality of adult inpatients with COVID-19 in Wuhan, China: a retrospective cohort study. Lancet 395(10229):1054-1062

5. Xie C, Jiang L, Huang G, Pu H, Gong B, Lin H, Ma S, Chen X, Long B, Si G, Yu H, Jiang L, Yang X, Shi Y, Yang Z (2020) Comparison of different samples for 2019 novel coronavirus detection by nucleic acid amplification tests. Int J Infect Dis 93:264-267

6. Centers for Disease Control and Prevention Division of Viral Diseases. CDC 2019-novel coronavirus (2019-nCoV) Real-time
RT-PCR diagnostic panel. https://www.who.int/emergencies/ diseases/novel-coronavirus-2019/technical-guidance/laboratoryguidance

7. Wang M, Cao R, Zhang L, Yang X, Liu J, Xu M, Shi Z, Hu Z, Zhong W, Xiao G (2020) Remdesivir and chloroquine effectively inhibit the recently emerged novel coronavirus (2019-nCoV) in vitro. Cell Res 30(3):269-271

8. Liu J, Cao R, Xu M, Wang X, Zhang H, Hu H, Li Y, Hu Z, Zhong W, Wang M (2020) Hydroxychloroquine, a less toxic derivative of chloroquine, is effective in inhibiting SARS-CoV-2 infection in vitro. Cell Discov 6(1):16

9. Bray F, Ferlay J, Soerjomataram I, Siegel RL, Torre LA, Jemal A (2018) Global cancer statistics 2018: GLOBOCAN estimates of incidence and mortality worldwide for 36 cancers in 185 countries. CA Cancer J Clin 68(6):394-424

10. Liang W, Guan W, Chen R, Wang W, Li J, Xu K, Li C, Ai Q, Lu W, Liang H, Li S, He J (2020) Cancer patients in SARS-CoV-2 infection: a nationwide analysis in China. Lancet Oncol 21:335-337

11. Kutikov A, Weinberg DS, Edelman MJ, Horwitz EM, Uzzo RG, Fisher RI (2020) A war on two fronts: cancer care in the time of COVID-19. Ann Intern Med. https://doi.org/10.7326/M20-1133

12. Liu XM, Wang DQ (2020 Feb) Consideration and suggestions on development of blood transfusion department under the epidemic situation of novel coronavirus pneumonia. Zhonghua Yi Xue Za Zhi 100(0):E013

13. Chang L, Yan Y, Wang L (2020) Coronavirus disease 2019: coronaviruses and blood safety. Transfus Med Rev. https://doi. org/10.1016/j.tmrv.2020.02.003

14. Kristian S, Todd M, Alireza M. Considerations in the triage of urologic surgeries during the COVID-19 pandemic. Eur Urol https://els-jbs-prod-cdn.jbs.elsevierhealth.com/pb/assets/raw/ Health\%20Advance/journals/eururo/EURUROL-D-20-003801584548684213.pdf

15. Furukawa K, Irino T, Makuuchi R, Koseki Y, Nakamura K, Waki Y, Fujiya K, Omori H, Tanizawa Y, Bando E, Kawamura T, Terashima M (2019) Impact of preoperative wait time on survival in patients with clinical stage II/III gastric cancer. Gastric Cancer 22(4):864 872

16. Visser E, Leeftink AG, van Rossum PSN, Siesling S, van Hillegersberg R, Ruurda JP (2016) Waiting time from diagnosis to treatment has no impact on survival in patients with esophageal cancer. Ann Surg Oncol 23(8):2679-2689

17. Bleicher RJ, Ruth K, Sigurdson ER, Beck JR, Ross E, Wong YN, Patel SA, Boraas M, Chang EI, Topham NS, Egleston BL (2016) Time to surgery and breast cancer survival in the United States. JAMA Oncol 2(3):330-339

18. Shin DW, Cho J, Kim SY, Guallar E, Hwang SS, Cho BL, Oh JH, Jung KW, Seo HG, Park JH (2013) Delay to curative surgery greater than 12 weeks is associated with increased mortality in patients with colorectal and breast cancer but not lung or thyroid cancer. Ann Surg Oncol 20(8):2468-2476

19. Fossati N, Rossi MS, Cucchiara Vet al (2017) Evaluating the effect of time from prostate cancer diagnosis to radical prostatectomy on cancer control: can surgery be postponed safely? Urol Oncol 35(4): 150.e9-150.e15

20. Khorana AA, Tullio K, Elson P, Pennell NA, Grobmyer SR, Kalady MF, Raymond D, Abraham J, Klein EA, Walsh RM, Monteleone EE, Wei W, Hobbs B, Bolwell BJ (2019) Time to initial cancer treatment in the United States and association with survival over time: an observational study. PLoS One 14(3):e0213209

21. Murphy CT, Galloway TJ, Handorf EA, Egleston BL, Wang LS, Mehra R, Flieder DB, Ridge JA (2016) Survival impact of increasing time to treatment initiation for patients with head and neck cancer in the United States. J Clin Oncol 34(2):169-178

22. Dolly D, Mihai A, Rimel BJ, Fogg L, Rotmensch J, Guirguis A, Yordan E, Dewdney S (2016) A delay from diagnosis to treatment 
is associated with a decreased overall survival for patients with endometrial cancer. Front Oncol 6:31. https://doi.org/10.3389/ fonc. 2016.00031

23. Jeon MJ, Kim WG, Kwon H, Kim M, Park S, Oh HS, Han M, Sung TY, Chung KW, Hong SJ, Kim TY, Shong YK, Kim WB (2017) Clinical outcomes after delayed thyroid surgery in patients with papillary thyroid micro carcinoma. Eur J Endocrinol 177(1):25-31

24. Froehner M, Heberling U, Zastrow S, Toma M, Wirth MP (2016) Growth of a level III vena cava tumor thrombus within 1 month. Urology. 90:e1-e2

25. Waldert M, Karakiewicz PI, Raman JD, Remzi M, Isbarn H, Lotan Y, Capitanio U, Bensalah K, Marberger MJ, Shariat SF (2010) A delay in radical nephroureterectomy can lead to upstaging. BJU Int 105(6):812-817

26. Baudin E (2015) Endocrine tumor board of Gustave Roussy. Adrenocortical carcinoma. Endocrinol Metab Clin N Am 44(2): 411-434

27. Kabir T, Syn N, Ramkumar M, Yeo EYJ, Teo JY, Koh YX, Lee SY, Cheow PC, Chow PKH, Chung AYF, Ooi LL, Chan CY, Goh BKP (2020) Effect of surgical delay on survival outcomes in patients undergoing curative resection for primary hepatocellular carcinoma: inverse probability of treatment weighting using propensity scores and propensity score adjustment. Surgery 167(2):417-424

28. American College of Surgeons. COVID-19:Elective case triage guidelines for surgical care. https://www.facs.org/covid-19/ clinical-guidance/elective-case/cancer-surgery

29. Society of Surgical Oncology/COVID-19 resources/Disease site specific management resources. https://www.surgonc.org/ resources/covid-19-resources

30. Indian Association of Surgical Oncology. Updated IASO COVID19 guidelines. https://iasoindia.in/wp-content/uploads/2020/03/ Official-IASO-COVID-19-Guidelines.pdf

31. Association of Anaesthetists (2020) Anaesthetic management of patients during a COVID-19 outbreak. https://anaesthetists.org/ Home/Resources-publications/Anaesthetic-Management-ofPatients-During-a-COVID-19-Outbreak

32. Ong S, Tan K (2020) Practical considerations in the anaesthetic management of patients during a COVID-19 epidemic. Anaesthesia. https://doi.org/10.1111/anae.15053

33. Sorbello M, El-Boghdadly K, Di Giancinto I et al (2020) The Italian COVID-19 outbreak: experiences and recommendations from clinical practice. Anaesthesia. https://doi.org/10.1111/anae.15049

34. Cook TM, El-Boghdadly K, McGuire B et al (2020) Consensus guidelines for managing the airway in patients with COVID-19. Anaesthesia. https://doi.org/10.1111/anae.15054
35. Dexter F, Parra MC, Brown J et al (2020) Perioperative COVID-19 defense: an evidence-based approach for optimization of infection control and operating room management. Anesth Analg. https://doi. org/10.1213/ANE.0000000000004829

36. Lie SA, Wong SW, Wong LT, Wong TGL, Chong SY (2020) Practical considerations for performing regional anaesthesia: lessons learned from the COVID-19 pandemic. Can J Anaesth. https://doi.org/10.1007/s12630-020-01637-0

37. Chan PKS, To KF, Lo AWI et al (2004) Persistent infection of SARS coronavirus in colonic cells in vitro. J Med Virol 74(1):1-7

38. Hu XH, Niu WB, Zhang JF et al (2020) Treatment strategies for colorectal cancer patients in tumor hospitals under the background of corona virus disease 2019. Zhonghua Wei Chang Wai Ke Za Zhi 23(3):201-208

39. Yu GY, Lou Z, Zhang W (2020) Several suggestions of operation for colorectal cancer under the outbreak of corona virus disease 2019 in China. Zhonghua Wei Chang Wai Ke Za Zhi 23(3):208211

40. Luo Y, Zhong M (2020) Standardized diagnosis and treatment of colorectal cancer during the outbreak of corona virus disease 2019 in Renji hospital. Zhonghua Wei Chang Wai Ke Za Zhi 23(3):211216

41. Chen YH, Peng JS (2020) Treatment strategy for gastrointestinal tumor under the outbreak of novel coronavirus pneumonia in China. Zhonghua Wei Chang Wai Ke Za Zhi 23(2):I-IV

42. Tian S, Hu W, Niu L et al (2020) Pulmonary pathology of earlyphase 2019 novel coronavirus (COVID-19) pneumonia in two patients with lung cancer. J Thorac Oncol. https://doi.org/10.1016/j. jtho.2020.02.010

43. Li X, Liu M, Zhao Q, Liu R, Zhang H, Dong M, Xu S, Zhao H, Wei S, Song Z, Chen G, Chen J (2020) Preliminary recommendations for lung surgery during 2019 novel coronavirus disease (COVID19) epidemic period. Zhongguo Fei Ai Za Zhi. 23(3):133-135

44. Xu Y, Liu H, Hu K, Wang M (2020) Clinical management of lung cancer patients during the outbreak of 2019 novel coronavirus disease (COVID-19). Zhongguo Fei Ai Za Zhi 23(3):136-141

45. Jiang ZF, Li JB (2020) Ten hot issues on diagnosis and treatment of breast cancer under the outbreak of novel coronavirus pneumonia. Zhonghua Yi Xue Za Zhi 100(10):721-723

Publisher's Note Springer Nature remains neutral with regard to jurisdictional claims in published maps and institutional affiliations. 